\title{
Challenging the Grounding Objection to Presentism
}

\section{Rognvaldur Ingthorsson}

\author{
Lunds University \\ Department of Philosophy \\ Sweden \\ rognvaldur.ingthorsson@fil.lu.se
}

Article info

CDD: 115

Received: 26.02.2017; Accepted: 16.03.2017

DOI: http://dx.doi.org/10.1590/0100-6045.2017.V40N1.RI

\author{
Keywords \\ Presentism \\ Grounding objection \\ Truthmaker principle \\ Ontology of Time
}

\begin{abstract}
The grounding objection to presentism rests on two premises: (i) every true proposition $P$ has a truthmaker $T$, and (ii) some claims about the future and past are obviously true. However, if the future and past do not exist, there can be no truthmakers for future and past tensed expressions. Presentists tend not to challenge the premises of the objection. Instead they argue that the present contains all the truthmakers we need. Presentists should challenge the premises instead. First, finding truthmakers in the present only results in the postulation of implausible and/or ethereal entities that ultimately fail to solve the grounding objection. Second, no manifestly absurd consequences follow from accepting the lack of truth-values for tensed expressions. Third, the grounding objection does not just require the assumption that for every truth there is a truthmaker, but also that for every truthmaker there is a truth. I show how one can deny the latter without denying the former.
\end{abstract}

Manuscrito - Rev. Int. Fil. Campinas, v. 40, n. 1, pp. 87-107, jan.-mar. 2017. 


\section{Introduction}

The grounding objection (see, e.g. Crisp 2007; Kierland 2013) is one of the main objections to presentism, the view that only the present exists; the future does not exist yet, and the past no longer. The objection takes its departure from two premises, (i) that every true proposition $P$ has a truthmaker $T$, and (ii) that some of our claims about the future and past are obviously true. It is then argued that if the future and past do not exist, there can be no truthmakers in the future and past to make expressions about the future and past true, and then those expressions will lack truth-values. In this paper I will treat the objection as if it only concerns past tensed expressions. It simply isn't as widely accepted that future tensed expressions must also have a truth-value. If a solution is found for the past, the future will not be a problem.

Presentists tend not to challenge the two assumptions on which the objection is based. Instead they argue that by denying the past they are not denying the existence of truthmakers for tensed expressions; the truthmakers only appear to be in the past, but really are in the present (for instance, Prior 1962; Bigelow 1996; Craig 2000; Cameron 2015). I call this the relocation strategy, because the strategy is to relocate the subject matter of these expressions from the past to the present in order to save the truth of tensed expressions.

I will first argue that the relocation strategy is a bad strategy, and then consider in what way one could challenge the premises on which the objection is built, rather than the conclusion. Very briefly, the relocation strategy leads to the postulation of a plethora of ethereal entities that go against the grain of presentism as a very down-to-Earth and concrete sort of view (one that fits our everyday view of the world), and ultimately doesn't answer the grounding objection anyway. Finally, I will argue that there are no manifestly absurd consequences that follow from accepting that expressions about the past lack truth-values. I will not challenge the view that for every truth there is a truthmaker, but illustrate that the grounding objection requires in addition what really is a separate claim but often believed to be a corollary of the former, notably that for every truthmaker there is a truth.

Manuscrito - Rev. Int. Fil. Campinas, v. 40, n. 1, pp. 87-107, jan.-mar. 2017. 


\section{The Relocation Strategy}

As Brian Kierland points out (2013), there is a very plausible idea behind the relocation strategy, notably that everything that happens in the present leaves a mark on reality, which is then preserved in the world as it endures in the present. Accordingly, the idea is that for any putative truth about the past, we find something in the present that might reasonably count as a mark of the past. The question is then of course what these marks are, and, which we will return to later, can our beliefs about the past really be made true by such marks?

Obviously, this solution won't work for the future, because the future has yet to leave a mark on reality. That, however, may be seen as an advantage because even B-theorists are tempted to think that the future is open and undetermined. I will focus on the past in what follows, since the lack of truth-values for past tensed expressions is a much greater problem compared to the lack of truth-values for future tensed expressions. If we can solve the problem for the past, the will be no problem with future tensed expressions.

What kind of truthmakers can we find in the present to ground the truth of expressions about the past? One suggestion, due to Arthur Prior, is that expressions about the past do not refer to any particular concretely existing state of affairs, but to some general feature of the present, but he is very vague about what this feature is:

the fact that Queen Anne has been dead for some years is not, in the strict sense of 'about', a fact about Queen Anne; it is not a fact about anyone or anything - it is a general fact. Or if it is about anything, what it is about is not Queen Anne-it is about the earth, maybe, which has rolled around the sun so many times since there was a person who was called 'Anne', reigned over England, etc. (Prior 1962: 13)

Please note that by 'fact', Prior means something like 'true proposition', i.e. a truthbearers, whereas what they are 'about' would be the truthmaking feature of the world. 'Fact' is also used to denote the truthmaking features of the world, rather than the truthbearers. Anyway, in Priors terminology, 'facts' about the past constitute the set of beliefs

Manuscrito - Rev. Int. Fil. Campinas, v. 40, n. 1, pp. 87-107, jan.-mar. 2017. 
that are putatively true and thus in need of a truthmaker. Prior admits he isn't too sure what the truthmaking features are, it might even be the whole world, which is why his position is sometimes called global property presentism (Kierland 2013).

Prior's suggestion bears close affinity to the way C. D. Broad proposed to resolve the problem for future tensed expressions. Broad suggested that we are misled by the grammatical similarity between future and present tensed expressions. Both appear to be attributions of certain characteristics to particular existents. Compare, say, 'the Queen is looking charming tonight' and 'the Queen will be charming on her $100^{\text {th }}$ birthday'. Instead, he suggests, in talking about the future, even when we are using given names, we are in fact only making predictions about the likely occurrence of a generic type of becoming, but not talking about any particular becoming. Here is how Broad explains what it would have meant for William III to express 'Queen Anne's death, is future', when the Queen was still alive:

What William did was to make a peculiar kind of assertion about becoming and about the characteristic of being the death of Queen Anne. He asserted that the sum total of existence would increase by further becoming, and that some part of what would thus be added would be characterised as the death of his sister-inlaw. He was neither talking about nor referring to that particular event which did in fact eventually become, and which, when it became, was in fact characterised as the death of Anne. For, when he made his judgment, there was no such event in the whole of reality for him to talk about or to refer to (1923: 80-1).

Accordingly, statements about the future are not about anything existing in the future, but are instead statements that describe our expectations that some generic type of event will come into being. These expectations are neither true or false, but can be more or less justified.

I think it is important to note that Broad's point is not really grammatical. He is not arguing that the future doesn't exist because this is somehow implied by the true grammar of future tensed expressions. Consequently, he is not discovering the misleading character of ordinary language by an analysis of language. No, it is his appraisal of the

Manuscrito - Rev. Int. Fil. Campinas, v. 40, n. 1, pp. 87-107, jan.-mar. 2017. 
ontology of time, i.e. that the future does not exist, that implies that that the grammar of future tensed expressions must be misleading, and he consequently invents another way of understanding what the expression could be interpreted as saying, which accords with his ontology. Indeed, we now know that the grammar of the expression 'the sun rises' is misleading, because the sun does not really possess the characteristic of 'rising'. In this case we discovered something about grammar because we discovered something about the world.

Prior can be understood to make roughly the same suggestion about how we must change our understanding of the grammar of past tensed expressions to fit the ontology he prefers, notably to understand past tensed expressions as general descriptions of the world. The difference is that Prior does not only want to tell us how to understand the meaning of past tensed expressions, but also to understand in what sense they are true. Consequently, Prior needs to find truthmakers whereas Broad doesn't. But, he is really at a loss as to what exactly these truthmakers are.

Prior's position can be criticised for turning the world as a whole, or great big chunks of it, into some kind of default truthmaker for all expressions about the past. Surely, the claims 'Queen Anne's death was peaceful' and 'dinosaurs roamed the Earth', if true, are made true by different things. As a suggestion about truthmakers, it is just too vague. Furthermore, which will be relevant later on, it doesn't even say which features of the present would inform us about what the world used to be, and hence doesn't explain in what sense Queen Anne's death has lefts its mark on reality such that it is a part of how the world is now. We don't infer that Queen Anne has been dead for some time now from some general feature of the world, but from the fact that her death is documented in various ways in historical records. So, the historical record, and its endurance in the present from the time of her death until now, would be a much more straightforward example of how Queen Anne's death has left its mark on reality, and which would justify the truth of our beliefs about Queen Anne's death. Fossilised remains of dinosaurs would represent the particular marks left on reality by the dinosaurs of the past, preserved in what could be called the natural 
record of the past. We then have two distinct marks for the death of Queen Anne and for the existence of dinosaurs.

Other philosophers have tried to offer more specific entities to serve as truthmakers. For instance, W. L. Craig suggests the possibility that 'Socrates was wise' refers to an 'individual essence' of Socrates, which is a kind of abstract entity that could exist presently even if Socrates himself does not exist (Craig 2000: 199). One can complain that this is on the one hand too arbitrary, and on the other that individual essences of this kind do not inform us about the past. It is easy to postulate that everything that comes to be in the present leaves an incorporeal trace of itself that somehow endures in the present thereafter. However, it converts presentism from being one of the sparsest ontological doctrines of all, into something much less sparse. In addition to the present being constituted by the current state of the world, it also consists of the incorporeal individual essences left by every becoming in the history of the universe. I don't have a knock down argument against such a view. The best I can do is to challenge the need to make such a postulation.

\section{Incorporeal, General and/or Abstract Truthmakers}

The first point to note is that these incorporeal, general, and abstract features that presentists are postulating are an addition to reality that cannot be empirically discovered and/or verified. As such they are difficult to understand as marks left on reality that inform us about the past; they appear instead as arbitrary postulations about the world having some required feature to make some or other expression about the past true. In other words, we infer from our belief that some propositions $p$ about the past is true, that the world must at present bear some feature $T$ that makes that belief true, rather than inferring from an existing feature $T$ that $p$ is true. Not only is it arbitrary, it simply isn't in conformity with what we actually do in justifying the truth of expressions about the past. We justify our beliefs about what the past used to be, by appealing to the historical and natural record. This record exists concretely in the present, whether in the form of various man made artefacts (books, audio recordings, photos, films, archaeological remains, etc.) or natural remains

Manuscrito - Rev. Int. Fil. Campinas, v. 40, n. 1, pp. 87-107, jan.-mar. 2017. 
such as fossils, layers of soil and rock, oil, etc. Nobody says that Socrates was wise because this is evident from his individual incorporeal essence, but because of what we learn from the historical record.

Another way to complain about the same thing, due to Theodore Sider, is to say that past tensed expressions, on this understanding, are understood as property ascriptions that are peculiarly 'backward orientated'; they signify what something was in the past, but not what that something is now such that it makes some or other expression true (Sider 2001). Two examples of property ascriptions of this kind are 'having been 4ft tall' (Cameron 2015: 134), and 'previously containing dinosaurs' (Sider 2001: 41). It bears to mention that Cameron and Sider are assuming that these expressions are not just another way to say 'this $6 \mathrm{ft}$ person once was $4 \mathrm{ft}$ tall' or 'these fossils tell us there once were dinosours', but are actually ascribing to something a property of 'having been' something or other, which is distinct from what it is now.

A more concrete suggestion is that the only thing that is needed to be a mark of the past, is the concrete and determinate state of the world at that time. This seems to have been the core idea in Stoic presentism, if we are to believe Bigelow's account of them (1996). One example Bigelow borrows from Sextus Empiricus is this: "if this man has a scar, this man has had a wound" (1996: 41). Consequently, if we perceive that a man instantiates the property of having a scar now we can infer that he has had a wound in the past. I find it difficult to tell whether Empiricus means the latter part of the sentence to be an ascription of the property of 'having had a wound' to the scarred man, but at least he is saying something about the presently existing grounds we may have for believing something about the mans past. The question is if our grounds for believing $p$, must be the same as what grounds the truth of $p$.

On this suggestion, we are able to derive information about the past from the way things are at present, using our knowledge of the laws of nature. To do this we don't need to postulate the existence of incorporeal, general, or abstract entities. The laws of nature in turn are perfectly befitting a presentist ontology, because the world instantiates them at any given time. In theory then, if we knew the present state of the world in detail, and the laws of nature governing the world, we could

Manuscrito - Rev. Int. Fil. Campinas, v. 40, n. 1, pp. 87-107, jan.-mar. 2017. 
deduce what the world used to be like. Kierland calls this view nomic presentism (2013).

\section{Nomic Presentism and Grounding}

I find two problems with the viability of a nomic presentist solution to the grounding objection (see also, Ludlow 1999; Bourne 2006). Kierland has another objection based on what he calls the record constraint (2013), which I will discuss in section 5 below. The first problem I have is that a nomic presentist solution requires the world to be completely causally determined. If it were not, information would not be passed on in a transitive fashion from the distant past to the present. The solution requires that each state of the universe must pass on-in an unbroken chain-information not just about itself and each immediately preceding state, but about every stage so far; about the Big Bang, the dinosaurs, and who authored King Lear. The problem is that even if we now may be in a position to extract information about the past, then we have also rendered the future as fixed and determined, instead of being indeterminate and open. I find this to be an unwanted consequence in itself, independently of the grounding objection.

The second problem is that even if we accept causal determinacy and therefore are in a position to extract information about how the world used to be, then I don't see that this really grounds the truth of our beliefs about the past in the way truth is typically assumed to work, notably by correspondence of truthbearer to truthmaker. This is because the state of the world at present-no matter how much it owes is characteristic to the past - can only be the past by proxy, and, as a rule, does not correspond to the way we believe the past used to be. To say that the belief that I was four feet tall when I was twelve corresponds to me standing six foot tall today, violates my idea of how the content of an expression corresponds to fact. If presentists are to insist that such beliefs are nevertheless made true by the world as it is now, they must surely be relying on some altogether different notion of truth than correspondence.

Manuscrito - Rev. Int. Fil. Campinas, v. 40, n. 1, pp. 87-107, jan.-mar. 2017. 
There are indeed other views about truth that do not require the existence of whatever a proposition is about, but I don't see them working for the presentist because none of these accounts make the presently existing mind-independent reality be the truthmaker of any expression. The coherence and pragmatic theories of truth do not explicitly require the existence of the concrete entities that the expressions refer to; they simply do not depict truth as reliant upon what the world is like at present. The deflationary theory is arguably a rejection of truth tout court, and the identity theory would have truth to be the identity of a belief to a true proposition, not to the world. The latter may work for some forms of erzatsist presentism, but not nomic presentism. The suggestion will only work if we understand 'making true' either in some altogether new and primitive way, or as including various forms of justification as means for making a proposition true (which is of course what epistemic theories of truth are arguing). I have yet to see presentists take an explicit stand on this issue and won't speculate further at this point in time about where that will lead. Instead I will turn to consider whether there really are any insuperable difficulties involved in denying that expressions about the past have truth values, in particular whether it has any consequences for our prospects of justifying our beliefs about the past, say, that dinosaurs roamed the earth. But first a quick word about Kierland's worry about nomic presentism, based on what he calls the record constraint.

\section{The Record Constraint}

The record constraint is a set of four criteria for what could count as a record of the past preserved in the present (Kierland 2013: 181). The first two constraints are reasonable criteria for nomic presentism, notably that (i) the record must be an effect of the past, and (ii) it must be a complete record of the past. Note that the second is only fulfilled if the world is causally determined. However, I have doubts about the other two, which are based on Kierlands "hazy thought that this record doesn't just happen to be such a record, rather its very 'purpose' is to be such a record; in other words, there is such an effect only because it's

Manuscrito - Rev. Int. Fil. Campinas, v. 40, n. 1, pp. 87-107, jan.-mar. 2017. 
part of the very 'construction' of reality that it keeps a record of its own history" (Kierland 2013: 180). From this hazy thought, Kierland suggests that the record must also (iii) be a certain imprint that the present makes on a record-keeping medium, and (iv) that it must be sui generis in the sense that it has no other role than keeping record. From the last two constraints Kierland infers that it shouldn't require advanced mathematics to recover from the record the information about the past, and so laws of nature should not play a role in the extraction of information about the past, and/or in the grounding of truths about the past.

In the absence of an argument to justify the 'hazy idea', I take it that a nomic presentist is free to simply disagree with the plausibility of Kierland's criteria. First of all, why add a special medium to do the job material reality is already doing, especially if the medium then arguably is useless to us as a record of the past; we cannot extract information about the past from such a record, whether it be with the use of mathematics or anything else. If the state of the world at a given present is an effect of the past, and the world is causally determined, then this should be enough for the concretely existing present to 'manifest' everything that is needed to extract (or construe) information about the past in the epistemic sense. Why must there be a separate sui generis record that somehow does the same thing? And why must there be some constraints on what our epistemic practices require to extract information about the past, other than those determined by the nature of reality? Kierland offers no argument for this.

To my mind, the demand for a sui generis record keeping medium, is a demand for an incorporeal, general, and/or abstract addition to reality, and one from which it is entirely unclear how any information could be retrieved except by the postulation of some form of faculty of intuition that can grasp the imprints in the record keeping medium independently of any empirical enquiry. Indeed, it is also a mystery how material entities can make an imprint on such an incorporeal medium, and so knowledge about the past would be beyond the reach of any existing scientific discipline. As far I can see, we would have a presentism on which it is perhaps possible to have true beliefs about the past (they can correspond

Manuscrito - Rev. Int. Fil. Campinas, v. 40, n. 1, pp. 87-107, jan.-mar. 2017. 
to the imprints in the record), but no justification for their truth other than intuition.

\section{True vs. Justified Beliefs about the Past}

Even though presentists deny the existence of the past, they acknowledge the existence of everything that any scientific discipline de facto appeals to right now in their justification of theories/hypotheses about the past-man made documentation, fossils, evolution theory, knowledge of the laws of nature-because they all obtain now. Let me call this the historical record. Consequently, justification is no problem. We can falsify theories/hypotheses about the past that don't fit the historical record, and choose to believe on rational grounds the theories/hypotheses that do fit. But, according to the hypothesis under consideration, these beliefs about the past cannot correspond to anything because the past no longer exists. Does this mean that we cannot say that we have knowledge about the past? Well, it would imply that our knowledge about the past is at best hypothetical, which is what we already acknowledge about our knowledge about the past, just as we acknowledge about our knowledge of the present and future; knowledge is admitted to be fallible. If knowledge is justified belief that is also true, knowledge is by definition infallible.

More than anything, this problem revolves around the philosophical question of how exactly to understand knowledge. It does not concern the epistemology of the past or our current epistemic practices. No A- or B-theorist argues that we find out about the past in any other way than by inferring it from the historical record as it exists at any given time. That simply is the way science works. As a consequence nothing in this discussion has any implications for how we learn about the past, or, in other words, how we construe our knowledge about the past. It will only have implication for our general attitude towards the past, in terms of whether we believe it exists or not, and with our understanding of knowledge generally speaking. I will focus on the latter question, which I understand to be a question of whether we can allow knowledge to come

Manuscrito - Rev. Int. Fil. Campinas, v. 40, n. 1, pp. 87-107, jan.-mar. 2017. 
in degrees; is some knowledge both justified and true, and is some knowledge only justified?

The first thing to note that a conception of knowledge about the past as only justified but not true, is not equal to a conception of knowledge about the present as only justified but not true. If we believe something about the present on the basis of the available evidence, but it fails to correspond to reality because the available evidence was incomplete, then our belief is false because it represents reality as it really isn't. However, if we believe something about the past on the basis of the available evidence but it fails to correspond to reality because the past has ceased to exist, this does not mean that the belief represents the past as it really wasn't. Sure, to make this argument really stick, one would have to develop a theory of falsemaking, which I will not do here. However, I think the point is intuitively clear enough for my present purposes, notably that lack of truthmakers for past tensed expressions does not make our ideas about the past into misrepresentations of the past, but the lack of truthmakers for present tensed expressions will inevitably mean that these expressions misrepresent reality.

Second, the idea that knowledge has to be true and justified is already too strict to comply with received views about what counts as knowledge. We generally call everything knowledge that strikes us as justified on the basis of the available evidence, never mind whether it actually is true. We even call some things knowledge that we know is false. Take classical mechanics as an example. We know that classical mechanics is at best a useful approximation to reality, but it continues to be a staple in physics education and continues to be called knowledge. It continues to be a part of the curriculum because it is so useful and much easier to apply in the situations where it is known to give the same results as quantum mechanics and theory of relativity respectively. At the very least, our beliefs about the past that are justified by the historical record would continue to be called knowledge even if we agree it cannot correspond to a past that no longer exists. Otherwise put, the concept of knowledge that is already in use, is one that allows of degrees.

On a related note, some may worry that the lack of truth-values for expressions about the past implies that the past is indeterminate. Statements about the past are popularly believed to have determinate

Manuscrito - Rev. Int. Fil. Campinas, v. 40, n. 1, pp. 87-107, jan.-mar. 2017. 
truth-values because once things happen in a certain way in the present there is no way to undo or change it. However, I can't see that truth has much to do with determination. For mind-independent reality to be determinate, it is not required that there be propositions about it with determinate truth-values, nor is it required that the past be determinate for it to be true that whatever happens in the present is determinate and can never be undone. It is enough to know that what happens in the present is always determinate for us to know that what happened in the past also was determinate, because when it happened it was present and thus determinate. This conclusion holds whether or not we know anything about the past. The intuition that once things have happened, they can never be undone, is satisfied perfectly well by the consideration that once things have happened and ceased to exist, they cannot be undone; you cannot go back to a non-existent past to undo it. And anyway, it is supposed to be the case that propositions have determinate truth-values because reality is determinate, not the other way around.

So, would it be so outrageous to suggest that the idea of knowledge being true justified belief may perhaps be useful as a regulative idea for what we ideally strive towards, but fails to demarcate between what is today counted as knowledge and what doesn't. All things considered, it would seem a little thing to allow our beliefs about the future and past to be called knowledge, if the available evidence justifies them, even if they cannot in principle correspond to anything. I take it to be an open question still, in epistemology, whether knowledge is to be demarcated in terms of true justified belief or not. Consequently, philosophy of time should not decide in favour of one particular theory of time on the basis of a premature stance on what is the correct view of knowledge. That would be a case of letting one epistemic position override any metaphysical concerns, to settle a metaphysical issue.

Nomic presentism still strikes me as the best option available, although I prefer one that does not assume that reality is completely causally determined. I am perfectly happy with an approximate knowledge of the past, so would not worry if it is possible for some information to be lost, say, about the exact date at which life came into being on Earth, or who really wrote the poetic Edda. It is a view of reality as only comprising the concrete present, and yet allows us to make 
good predictions about the future, and to arrive at justified beliefs about the past. However, we have yet to consider ersatzist presentism, which has been suggested as the best way to answer the grounding objection, e.g. by Bourne (2006), and Wütrich (2012).

\section{Ersatzist Presentism and Grounding}

To my mind, Ersatzist presentism differs from other presentist views, because it is not clear that it is motivated by the idea that the past leaves a mark on the present. Instead it appears to be driven by the desire to find a way for the presentist to talk about non-present things, even if she denies their existence:

But it can hardly be contested that it is perfectly reasonable to ask presentism to characterize, or describe, what is the sum total of physical existence according to it. Just as in the debate on whether possible worlds should be reified, one can then insist that there is a position to be had in the temporal case analogous to ersatzism about possible worlds. Such an ersatzist presentism would admit merely non-present events only as abstract entities that lack any physical existence, introduced solely for representational purposes (Wütrich 2012).

I think one can understand erzatzist presentism as an attempt to make presentism compatible with the idea that there must be a complete description of the world (see, for instance Dummett 1960; Smith 2011). The ersatizt solution is to claim that at each present moment there exists, for every future and past time, a set of propositions representing the state of the world at that time (Bourne 2006; Crisp 2007; Wütrich 2012). However, it seems to me that the idea that ersatzist presentism can resolve the grounding objection by offering a complete description, is based on the hope that a complete description not only serves the function of a representation introduced solely for representational purposes' but also to serve as truthmaker for claims about the future and past. I don't see how that can work. Abstract entities, especially those merely invoked for representational purposes just aren't the right kind of

Manuscrito - Rev. Int. Fil. Campinas, v. 40, n. 1, pp. 87-107, jan.-mar. 2017. 
entities to serve as truthmakers. Indeed, as Joshua Mozersky (2015: 44) points out, to postulate abstract entities to serve as truthmakers for expressions about the future and past, will threaten to reverse the ontological priority of the present. Truth is supposed to be grounded in the concretely existing present, but on this view truth is largely grounded on abstract representations of non-existent futures and pasts.

I find it difficult to see how ersatz presentism can be made compatible with the above mentioned core idea of presentism. Admittedly, ersatz presentism is compatible with the idea that the sets of propositions that pertain to the past are marks left on an incorporeal and/or abstract medium, but that view faces the difficulties outlined above about the relationship between the concrete reality and an incorporeal record, and what kind of truth theory is at play when expressions in the present about the past are made true by corresponding to an incorporeal mark of the past.

\section{What's So Special About the Grounding of Truth Anyway?}

Above I have tried to show that nothing good comes from the struggle to find truthmakers in the present. I have also argued that the conclusion of the grounding argument isn't all that bad, there is nothing inherently wrong with there being no truths about the past. Now I turn to argue that the grounding objection will only work if one accepts a very strong reading of the truthmaking principle-which admittedly is the popular reading - and which on closer inspection turns out to be an implausible reading, wherefore we have further reasons to treat the grounding objection as inconclusive.

The truthmaking principle, in its simplest form, merely states that for every truth there is a truthmaker, which is simply an expression of the idea that the truth-value of propositions is determined by the features of reality that the propositions are about. As such the truthmaking principle is not just intuitively plausible but a logical consequence of the correspondence theory. However, a number of thinkers have felt a need to add what is meant to be a corollary, supposedly explaining, or completing, the principle, and have ended up saying that a truthmaker is 
something whose very existence necessitates the existence of a true proposition about it. So for instance, in AWorld of States of Affairs Armstrong states that "the truthmaker for a truth must necessitate that truth" (1997: 115), which can be read as saying merely that the truth of a proposition is necessitated by the truthmaker, but not the existence of the proposition itself. However, in Truth and Truthmakers Armstrong makes it clear that he thinks the truthmaker not only makes an existent proposition true but makes it exist:

$p$ (a proposition) is true if and only if there exists a $\mathrm{T}$ (some entity in the world) such that $\mathrm{T}$ necessitates that $p$ and $p$ is true in virtue of T (Armstrong 2004: 17)

In other words, he ends up saying something equivalent to:

For every truth there is a truthmaker; for every truthmaker there is a truth

As I have argued elsewhere in much more detail, we are dealing with two distinct principles that do not entail each other, and the latter is not at all intuitively plausible (Ingthorsson 2006). The first part is based on the idea that the truth-value of propositions is determined by the facts, but the second is based on the idea that, necessarily, if there exists a fact there also exists the corresponding proposition. Hence there must be an independent reason for the assumption that for every feature of reality there is a corresponding proposition about it; i.e. there must be an independent reason for becoming a Platonist.

Very few, except Armstrong himself, seem to have noticed that the stronger form of the truthmaker principle implies Platonism. For an immanent realist like Armstrong, this is serious trouble. He can't allow himself of abstract propositions, wherefore he initially construes them as representational states of minds (Armstrong 2004: 14). But, to him, this is unsatisfactory, in particular because he believes there could be a world without minds that nevertheless would be a world where every truthmaker necessitated a truth. If propositions are representational states of mind, then in the absence of minds, there are no propositions and hence no truths (in the sense of propositions that correspond to

Manuscrito - Rev. Int. Fil. Campinas, v. 40, n. 1, pp. 87-107, jan.-mar. 2017. 
fact). For him it is intuitively evident that when there are no minds there are still truths, and appeals to Newton's image of an ocean of undiscovered truths for support:

Cannot there be truths which nobody has or will believe, or even formulate, much less state? Consider Newton and his image of the ocean of undiscovered truth that he said lay before him, reaching far beyond his own discoveries. We understand this well enough, and would continue to understand it even in the absence of an all-knowing creator or the ocean of truth yielding up all its secrets in the future. We may call such truths unexpressed truths. Generalising to include falsehoods, we can speak of 'unexpressed propositions'. True unexpressed propositions will be truths without any concrete truthbearers $[\ldots]$ They are, for me at least, conceptually very important. The reason for this is that the concept of such truths is needed to make sense of Truthmaker Necessitarianism (2004: 15).

In his search for a "this-worldly account of propositions" (2004: 12), in order not to violate his immanent realism, Armstrong appeals to what Stephen Read calls 'expressibility', the idea that there exist unexpressed propositions (Read 2000). Such entities, it is suggested, are real merely in virtue of the mere possibility of believing or contemplating or linguistically expressing something, and this possibility is in turn manifested in the concrete existence of whatever it is that could be believed, contemplated, or expressed. Basically he is saying that if there exists, say, a neutrino in motion through space, there exists the possibility of expressing that it exists and has such a such a state of motion.

Armstrong is stretching his immanent realism to the limits, and he is well aware of this. One particularly interesting worry discussed by himself is the danger of introducing uninstantiated properties into his ontology in the form of the uninstantiated content of an unexpressed proposition. Armstrong hopes that a deflationary account of these uninstantiated properties can be given, by equating them with the mere possibility of the instantiation of such a property. But, he does not mention the danger of making truth itself an uninstantiated property. When in fact there are no thinking beings, and hence no expressed

Manuscrito - Rev. Int. Fil. Campinas, v. 40, n. 1, pp. 87-107, jan.-mar. 2017. 
propositions, there will be no concrete truthbearers actually bearing the relational property of being true. Armstrong admits as much. He admits that truthmakers can only actually necessitate possible intentional objects, which, were they to be actually realised by minds, could actually bear the property of corresponding to its subject matter (Armstrong 2004: 16).

To my mind, even though we admit that in the absence of minds there still exists the mere possibility of expressing a proposition about some fact, i.e. there exists an unexpressed proposition, which would have corresponded to its subject matter in case it had been expressed, then the lack of an actual truthbearer is equal to the absence of truth. There would be the possibility of truth, but no truth; possibility is not equivalent to an actuality. There would be no truth in the very same way as there would be no thinkers, and there would be the possibility of truth in the very same way as there would be the possibility of being thinkers. Indeed, unless there was the possibility of there being thinkers there would not be the possibility of there being expressed propositions, and that would seem to cancel the existence of unexpressed propositions.

I disagree with Armstrong about the mind-independence of truth, but my reason for disagreeing with him is not because I find his theory unintelligible or inconsistent. I disagree because I do not share his enthusiasm for preserving truth at all cost, for two reasons. Firstly, for the sake of ontological economy. To assume that mind-independent reality consists only of determinate states of the world, and the possible ways the world could be different than it in fact is, seems more economical than to assume that in addition it must consists of possible ways of believing or contemplating or linguistically express the ways the world is or could be, even when there are no thinkers that could have believed or contemplated these ways. Especially since it is doubtful whether this assumption can establish that when there are no minds there are still actual truths; it can only establish the existence of the mere possibility of the instantiation of truths. It can only establish the necessary conditions for truth, but not sufficient conditions.

Secondly, I fail to see that it has been established beyond doubt that we need to assume that truth is mind-independent. For instance, we could say that what Newton intended to say, but formulated badly, was

Manuscrito - Rev. Int. Fil. Campinas, v. 40, n. 1, pp. 87-107, jan.-mar. 2017. 
that there is an ocean of undiscovered features of reality (not truths about them) waiting to be discovered, about which we know nothing. To deny that there is an ocean of undiscovered truths is not to deny that there is an ocean of undiscovered features of reality. Indeed, what does a scientist aim to discover? Does a physicist aim to discover all the unexpressed propositions that exist independently of her mind, or does she aim to discover the unknown determinate states and properties of the mind-independent world, and the laws of nature? Again we have a choice of making the world or an incorporeal medium of truths the focal point of our epistemic practices. It seems to me we have a chance of learning something from the world, but no chance of learning anything from the incorporeal medium.

In conclusion, embedded in the presuppositional depth-structure of the grounding objection lies an acceptance of Platonism about propositions. Without it we have no reason to accept the strong formulation of the truthmaker principle at play in the grounding objection. This is of course not strictly speaking an argument against the grounding objection, but I think it makes explicit an assumption required to make the objection stick, that previously was only implicit, and one that I suspect many have not been aware of. In other words, this may serve as nothing more than illustrating the cost of making the objection stick, but it wont deter anyone other than those who share a suspicion of Platonism.

\section{Conclusion}

This paper does not present any knock-down arguments to save presentism from the grounding objection. It is just a contribution to an on-going dispute, aimed merely at a better understanding of what is really at stake. On the one hand it serves to illustrate that the grounding objection relies on more assumptions than are typically made explicit, some of which may not appear palatable to either presentists or eternalists. This may weaken the force of the grounding objection. On the other hand it aims to show the weaknesses of the relocation strategy, as seen from within a presentist framework, and to argue that it may not

Manuscrito - Rev. Int. Fil. Campinas, v. 40, n. 1, pp. 87-107, jan.-mar. 2017. 
appear as absurd as many take it to be, to simply accept the conclusion of the grounding objection; expressions about the past lack truth values if presentism is true.

\section{References}

Armstrong, D. A World of States of Affairs, Cambridge: Cambridge University Press, 1997.

Armstrong, D. Truth and Truthmakers, Cambridge: Cambridge University Press, 2004.

Bigelow, J. The Reality of Numbers, Oxford: Oxford University Press, 1988.

Bigelow, J. "Presentism and Properties", Noûs 30, Supplement: Philosophical Perspectives 10, Metaphysics: 35-52, 1996.

Bourne, Cr. A Future for Presentism. Oxford: Oxford University Press, 2006.

Broad, C. D. Scientific Thought. London: Kegan Paul, Trench, Trubner \& Co. Ltd., 1923.

Cameron, Ross. The Moving Spotlight: An Essay On Time and Ontology. Oxford: Oxford University Press, 2015.

Craig, W. L. The Tensed Theory of Time: A Critical Examination. Synthese Library: Studies in Epistemology, Logic, Methodology, and Philosophy of Science, vol. 293. Dordrecht: Kluwer Academic Publishers, 2000.

Crisp, T. M. "Presentism and the Grounding Objection", Noûs 41: 90109, 2007.

Dummett, Michael. "A Defense of McTaggart"s Proof of the Unreality of Time", Philosophical Review 69: 497-504, 1960.

Ingthorsson, R. D. "Truthmakers without Truth", Metaphysica 7(2): 5371, 2006.

Manuscrito - Rev. Int. Fil. Campinas, v. 40, n. 1, pp. 87-107, jan.-mar. 2017. 
Kierland, B. "Grounding Past Truths: Overcoming the Challenge". In New Papers on the Present-Focus on Presentism, edited by R. Ciuni, K.Miller \& G. Torrengo. Philosophia Verlag, 173-209, 2013.

Ludlow, P. Semantics, Tense and Time, An Essay in the Metaphysics of Natural Language. Cambridge MA: MIT Press, 1999.

Mozersky, J. M. Time, Language, and Ontology. Oxford: Oxford University Press, 2015.

Prior, A. N. Changes in Events and Changes in Things. Lawrence, Kan.: University of Kansas Press, 1962.

Read, S. "Truthmakers and the Disjunction Thesis", Mind, 109: 67-79, 2000.

http://plato.stanford.edu/archives/fall2013/entries/lucretius/.

Sider, T. Four-Dimensionalism: An Ontology of Persistence and Time. Oxford: Oxford University Press, 2001.

Smith, Nicholas J. J. 2011. "Inconsistency in the A-Theory", Philosophical Studies 156: 231-47, 2011.

Wüthrich, C. "Demarkating Presentism", In H. de Regt, S. Okasha \& S. Hartmann (eds.), EPSA Philosophy of Science: Amsterdam 2009. Springer, pp. 441-50, 2012.

Manuscrito - Rev. Int. Fil. Campinas, v. 40, n. 1, pp. 87-107, jan.-mar. 2017. 